\title{
Indices of Habitual Fatty Acid Intake in Pre-Diabetic and Normoglycemic Individuals: A Population-Based Study
}

\begin{abstract}
Sônia Cristina Pereira de Oliveira ${ }^{1 *}$, Cássia Surama Oliveira da Silva ${ }^{2}$, Rafaella Cristhine Pordeus Luna $^{2}$, Thamires Ribeiro Chaves ${ }^{2}$, Mussara Gomes Cavalcanti Alves Monteiro', Keylha Querino de Farias Lima², Raquel Patrícia Ataíde Lima ${ }^{2}$, Jessica Vick Bernardo de Oliveira ${ }^{1}$, Débora Danuse de Lima Silva $^{2}$, Rejane Santana de Oliveira ${ }^{2}$, Alexandre Sérgio Silva ${ }^{1}$, Maria da Conceição Rodrigues Gonçalves ${ }^{1}$, Alcides da Silva Diniz ${ }^{3}$, Aléssio Tony Cavalcanti de Almeida ${ }^{4}$, Ronei Marcos de Moraes ${ }^{5}$, Roberto Teixeira de Lima ${ }^{1}$, Flávia Emília Leite de Lima Ferreira ${ }^{1}$ and Maria José de Carvalho Costa $^{1}$

${ }^{1}$ Postgraduate Program in Nutrition, Center for Health Sciences, Federal University of Paraiba, Brazil

${ }^{2}$ NIESN Interdisciplinary Studies in Health and Nutrition, Federal University of Paraíba, Brazil

${ }^{3}$ Postgraduate Program in Nutrition, Center for Health Sciences, Federal University of Pernambuco, Brazil

${ }^{4}$ Postgraduate in Applied Economic Science and Public Sector Economic, Center of Applied Social Science, Federal University of Paraíba, Brazil

${ }^{5}$ Postgraduate Program in Decision Models and Health, Department of Statistics, Center of Exact and Natural Sciences, Federal University of Paraíba, Brazil

*Corresponding author: Sônia Cristina Pereira de Oliveira, Postgraduate Program in Nutrition, Center for Health Sciences, Department of Nutrition, Federal University of Paraiba, Brazil
\end{abstract}

\section{ARTICLE INFO}

Received: 幽 February 10, 2020

Published: 乘 February 20, 2020

Citation: Sônia Cristina Pereira de Oliveira, Cássia Surama Oliveira da Silva, Rafaella Cristhine Pordeus Luna, Thamires Ribeiro Chaves, Mussara Gomes Cavalcanti Alves Monteiro, et al. Indices of Habitual Fatty Acid Intake in Pre-Diabetic and Normoglycemic Individuals: A PopulationBased Study. Biomed J Sci \& Tech Res 25(5)2020. BJSTR. MS.ID.004262.

Keywords: Consumption; Total Fat; Fasting Glycaemia; Pre-diabetes; Normoglycaemia

Abbreviations: ADA: American Diabetes Association; DM: Diabetes Mellitus; FA: Fatty Acid; CVD: Cardiovascular Disease; DRI: Dietary Reference Intakes; IGT: Impaired Glucose Tolerance; IBGE: Brazilian Institute of Geography and Statistics; DHA: Docosahexaenoic Acid; BMI: Body Mass Index

\section{ABSTRACT}

Introduction: The aim of the present study was to evaluate the amount and quality of fat consumed habitually by pre-diabetic and normoglycaemic adults.

Materials and Methods: A cross-sectional epidemiological study involving 233 individuals from the East and West Zones of the municipality of João Pessoa, Northeastern Brazil, was performed. Anthropometric, biochemical, food consumption, and lifestyle data were collected.

Results: There were no differences for demographic, socioeconomic, epidemiological variables, as well as for the variables of habitual consumption of fat and different types of isolated or associated fatty acids and lifestyle between the two groups. However, different relationships were observed in each group, between fasting blood glucose values and fat consumption, such as: in the pre-diabetic group there was an inverse relationship with fat consumption tertiles in relation to fatty acids (AG) monounsaturated (M) - (15.16 \pm $0.65 \mathrm{~g}$ and $24.11 \pm 2.74 \mathrm{~g})$ and Index I: S (I: S) $-(1.39 \pm 0.72 \mathrm{~g})$; and positive relationships with the consumption of the w-6:w-3 and w-6: w-9 indexes. In the normoglycemic group, inverse relationships were observed with the consumption of AGM w-3 and the w-3 total fat index and a positive relationship with the consumption of total polyunsaturated AG fats, indexes w-6: w-3, I: S w- 6: w-9.

Conclusion: It was concluded that there were no differences between the consumption variables for all types of fats between the two groups, but differences were observed in terms of the amounts consumed, especially regarding the indices between fatty acids, when relating these values of consumption in each group with fasting blood glucose values. Therefore, the quantitative needs of different types of fats to prevent the increase or reduction of blood glucose, are possibly different between normoglycemic and pre-diabetic. 


\section{Introduction}

According to the American Diabetes Association (ADA) [1], almost half of American adults have diabetes or pre-diabetes, which leads to a lower quality of life and a reduced life expectancy and imposes a burden on public health services. This reality is similar in both developed and developing countries. Among the factors associated with diabetes, dietary fat consumption stands out. According to the ADA [1], data on the ideal amount of total fat in the diets of people with diabetes are still inconclusive. A dietary plan emphasizing adequate amounts of Monounsaturated (MU), Polyunsaturated (PU), and saturated fats may improve glucose metabolism and reduce the risk of developing the disease. Research indicates that both the quality and the amount of dietary Fatty Acids (FAs) consumed have important roles in insulin resistance in type 2 Diabetes Mellitus (DM2). In addition, insulin resistance is a postprandial phenomenon linked to the metabolism of dietary fat [2]. Many researchers have analysed the relationships between FA intake and insulin resistance [3] and/or diabetes [4] and have contributed to this field of research by shedding light on potentially modifiable FA targets for the prevention or improvement of insulin resistance.

Recently, a study conducted to verify the variables associated with diet quality found that diabetes was associated with higher intake levels of unsaturated FAs and the Polyunsaturated FA (PUFA) omega $3(\omega-3)$ than total FA intake levels, suggesting that different FAs in the diet relative to total lipid consumption may be important molecular mediators that increase the risk of Cardiovascular Disease (CVD) [5]. In the Dietary Reference Intakes (DRIs, 2006), the reasonable $\omega-6: \omega-3$ ratio for adults ranges from $5: 1$ to $10: 1$; however, evidence to support this recommendation is insufficient, and the $\omega-6: \omega-3$ ratio is the only FA index cited by the DRIs [6]. Regarding the effects of dietary fat composition on insulin sensitivity, considerable evidence from animal studies indicates that saturated fats are harmful, while the FAs $\omega-3$ and $\omega-6$ improve the action of insulin [7]. Epidemiological studies and clinical trials have studied the roles of lifestyle and dietary factors (e.g., fat intake) in the prevention of diabetes [8].

Since insulin resistance is closely associated with dietary fat intake, dietary risk factors contributing to Impaired Glucose Tolerance (IGT), (i.e., just a pre-diabetes condition), both blood glucose altered fasting (IFG) as IGT (two pre-diabetic conditions), can be different from each other, just like those of DM2, can be influenced differently by dietary factors and can be treated effectively, if they are better understood. Considering that studies associating the consumption of fatty acids with diabetes reinforces the relationship with the types of unsaturated fatty acids, on the risk of morbidity, and these relationships may be lost by the analysis of individual fatty acids, an analysis of the proportion of consumption, represented by different indices between different types of fatty acids, can be a more consistent approach, since the analysis of comparison of diets in terms of individual nutrients should place the nutrient in a context of competition between them, for example: in the case of $\omega-6$ and $\omega-3$ that compete for the same enzymes, as well as the complex interaction between macros and micro nutrients [9]. Based on the consulted literature, this is the first study that aimed to identify and compare proportional relationships on the usual food consumption of different fatty acid indices in normoglycemic and pre-diabetic adults.

\section{Materials and Methods \\ Characterization of the Study}

This is an epidemiological, observational, analytical, crosssectional study, which does not allow establishing cause and effect or temporality relationship, although they are important in verifying risk factors and outcomes [10]. This cross-sectional study is linked to a population-based study entitled "Cycle II of Diagnosis and Intervention of the Food, Nutritional, and Non-Communicable Diseases Status of the Population of the Municipality of João Pessoa - PB (II DISANDNT-PB)" [11,12], which was conducted from May 2015 to May 2016.

\section{Ethical Issues}

The present study was submitted to and approved by the Research Ethics Committee of the Centre for Health Sciences (CCS for its acronym in Portuguese) of the Federal University of Paraiba (UFPB) under protocol no. 0559/2013 according to the ethical standards for research involving human subjects within Resolution 466 of December 12, 2012, of the National Health Council/National Research Ethics Committee. After identifying residences in randomly selected blocks located in the East and West Zones of the João Pessoa municipality, the researchers introduced themselves to the residents, described the objective of the study, and requested their participation in the study while respecting the ethical guidelines governing research with humans. The individuals selected for the study who agreed to participate signed an informed consent form.

\section{Sampling}

To perform this population-based study covering the East and West Zones of the João Pessoa municipality, a representative sample of adult subjects was established using information provided by the municipality, including a municipality map, the number of blocks per neighbourhood, and data from the Brazilian Institute of Geography and Statistics (IBGE) [13]. To calculate the sample, a single sampling procedure consisting of levels was used. Due to the presence of heterogeneity for the variable "income" and the relationship between income, the prevalence of diseases, and nutrition [14], stratified sampling [15] was used on the blocks at a first level. In this level, the neighbourhoods of the East and West Zones of the municipality were classified into four strata according to income level based on information obtained from the IBGE [13]. After stratification, the sample size was calculated, i.e., the number of representative blocks per zone. After determining the sample size, the weight of each stratum was calculated, and the number 
of blocks per zone was obtained according the zone's stratum. To obtain the weight of each stratum, the formula proposed by Silva, Moraes, and Costa [16] was used.

Considering an average income of BRL 2,213.26, a standard deviation of BRL 2,601.93, and a margin of error of BRL 3,320.00 for adults from the East and West Zones according to the "Cycle I of Diagnosis and Intervention of the Food, Nutritional, and NonCommunicable Diseases Status of the Population of the Municipality of João Pessoa - PB" (07/2008-01/2010), the minimum number of adults required for a statistically representative sample with a $95 \%$ confidence level was 236 . The total sample in this study included 233 adults distributed throughout the areas studied, one of whom met the exclusion criteria. The following inclusion criteria were used: an intact cognitive status, age between 20 and 59 years, normal fasting glucose levels, and the presence of prediabetes. Individuals with glucose levels below $60 \mathrm{mg} / \mathrm{dL}$ or greater than $125 \mathrm{mg} / \mathrm{dL}$, individuals with diabetes, individuals who used multivitamin and mineral supplements, and pregnant women were excluded from the study.

\section{Data Collection}

Home visits were performed by teams of undergraduate nutrition students and master's and doctoral students of the Graduate Programme in Nutritional Sciences (PPGCN for its acronym in Portuguese) of the UFPB who were properly trained prior to the beginning of data collection after conducting the pilot study. Questionnaires were used for demographic characterization, epidemiological characterization (self-reported hypertension and drug use), and lifestyle characterization (physical activity: those who performed more than 150 min of physical activity per week were considered physically active). Nutritional assessments and biochemical analyses were performed.

\section{Nutritional Assessment}

Weight and height measurements were performed in triplicate, and the average of the three values was used. The Body Mass Index (BMI) was then calculated as the body weight (kg) divided by the squared height of the body (metres), and the cut-off points for adults between 20 and 59 years of age were classified according to the World Health Organization (WHO) criteria [17].

\section{Lifestyle}

Physical activity, alcohol ingestion, smoking, and morbidity were considered in the evaluation of lifestyle. Participants were asked about the practice of physical activity (yes or no), including the modality, frequency (the number of times per week), and duration (in minutes), and information about alcohol consumption (how often six or more servings of alcohol were consumed on one occasion). Regarding smoking, individuals were asked whether they were smokers (yes or no) and whether they had smoked in the last six months. Self-reported smokers were also asked about the number of cigarettes consumed per day, week, or month. Self- reported former smokers were asked when they had stopped smoking. Patients were also asked about various morbidities (hypertension, diabetes, obesity, cardiovascular disease, and dyslipidaemia), whether they were diagnosed by a physician, whether a diagnosis was provided by a public or private physician, and whether medication was used, especially medications of interest for this research as well as anti-inflammatory agents and aspirin. All information was obtained through the epidemiological characterization questionnaire.

\section{Evaluation of Food Consumption}

Food consumption was assessed using the 24-Hour Recall (R24h) survey. This food survey was administered three times with a 15-day interval, and one day of the weekend was considered. To complete the R24h survey, individuals reported the following data: the time when food or beverages were consumed, the names of food or beverages consumed, detailed characteristics of the foods, such as the type, ingredients in the preparations, the brand, the form of preparation, and the amount consumed, which was reported according to portion sizes and household measurements. The R24h survey was applied using an album with pictures of food and four sizes of household measurements (small, medium, large, and extralarge), which were drawn based on the actual weight of the average food consumption validated for this population to more effectively quantify the sizes of consumed portions and minimize probable memory lapses of the individuals interviewed [18,19]. Foods mentioned in the R24h survey were transcribed and standardized in an auxiliary document. All foods were converted into grams using the manual of average real-sized portions based on Dietsys software for population-based studies [19].

Food preparations were separated according to their ingredients and amounts. Foods were evaluated using the Nutrition software DietWin 2013. This software has approximately 5,230 foods and recipes registered according to the TACO table $4^{\text {th }}$ version and the DIETWIN table, which are compilations of several tables from the IBGE and the United States Department of Agriculture USDA, respectively. For folate calculation, the Centre for Experimental and Applied Endocrinology (CENEXA, in Germany) General Food List and recipe technical files were referenced. In this study, the Multiple Source Method (MSM) was used, which was available online at the website (https://msm.dife.de/tps/msm/). The MSM is a statistical technique proposed by the European Prospective Investigation into Cancer and Nutrition (EPIC) [20]. This method includes two regression models, including one model for positive data regarding daily intake and another for sporadic consumption, and is applicable for nutrient and food intake.

\section{Statistical Analysis}

Initially, a descriptive analysis of habitual food consumption characteristics of the sample represented by the simple frequency using measures of central tendency and dispersion (the mean and standard deviation) was performed. Fat intake data were 
adjusted for energy according to Willet (1997). The data were evaluated for normality using the Lilliefors test, which is derived from the Kolmogorov-Smirnov test. Multiple regression analysis was performed with the variable's total fat, MUFAs, PUFAs, and the ratios of FAs per tertile of intake according to models 1 and 2. These regression models were adjusted for age, sex, BMI, income, education, and the presence of morbidities. Analyses of correlations between fasting blood glucose and habitual fat intake were performed in normoglycemic and pre-diabetic individuals. The statistical analysis was performed using the software STATA 13 , and a value of $\mathrm{P}<0.05$ was considered significant.

a) Model 1: Glycaemic levels $<100 \mathrm{mg} / \mathrm{dL}=\beta 0+$ the $2^{\text {nd }}$ tertile of consumption + the $3^{\text {rd }}$ tertile of consumption.

b) Model 2: Glycaemic levels $\geq 100$ to $125 \mathrm{mg} / \mathrm{dL}=\beta 0+$ the $2^{\text {nd }}$ tertile of consumption + the $3^{\text {rd }}$ tertile of consumption.

\section{Results}

An educational level above secondary education was noted in more than $80 \%$ of the total sample and in the groups of normoglycemic and pre-diabetic individuals. More than half of the sample earned an income above the median per capita income, and less than a third of the sample had 1-2 morbidities. Based on Table 1 , no differences in the following variables were found between the normoglycemic and pre-diabetic groups: sex, age, BMI, physical activity level, habitual fat consumption, and different types of FAs (combined or in isolation). According to the data in Table 2, in the group of normoglycemic individuals with habitual consumption classified in the second tertile of total fats (g), PUFAs (g), $\omega-6$ (g), and the indices $\omega-6: \omega-3$ (g:g), $\omega-6: \omega-9$, and U:S FAs (g:g), a positive correlation was observed between fasting glucose levels and the consumption of these fats.

Table 1: Normal dietary intake of total fats and indices of different types of fatty acids in the normoglycemic and pre-diabetic groups.

\begin{tabular}{|c|c|c|c|c|c|c|c|}
\hline & \multicolumn{2}{|c|}{$\begin{array}{c}\text { Total (normoglycemic and pre-diabetic } \\
\text { individuals) }\end{array}$} & \multicolumn{3}{|c|}{ Normoglycemic individuals } & \multirow{2}{*}{\multicolumn{2}{|c|}{$\begin{array}{c}\text { Pre-diabetic individuals } \\
\pm \text { SD }\end{array}$}} \\
\hline & Mean & $\pm \mathrm{SD}$ & Mean & $\pm \mathrm{SD}$ & Mean & & \\
\hline \multicolumn{8}{|l|}{ Habitual dietary fat intake } \\
\hline Total fat (g) and (\%) & $\begin{array}{c}53.72 \\
(28.38)\end{array}$ & \multirow{12}{*}{$\begin{array}{l}22.5 \\
-11.09 \\
11.1 \\
-3.53 \\
9.93 \\
-2.78 \\
7.02 \\
-0.3 \\
0.79 \\
-0.4 \\
5.23 \\
-1.38 \\
9.78 \\
1.12 \\
0.1 \\
0.71 \\
1.23 \\
0.92 \\
\end{array}$} & $\begin{array}{c}53.92 \\
(28.42) \\
\end{array}$ & $\begin{array}{c}22.52 \\
(11.00)\end{array}$ & $\begin{array}{c}53.12 \\
(28.27)\end{array}$ & \multicolumn{2}{|c|}{$\begin{array}{c}22.63 \\
(11.49)\end{array}$} \\
\hline Saturated FAs (g) and (\%) & $\begin{array}{c}16.93 \\
(12.63)\end{array}$ & & $\begin{array}{c}16.70 \\
(12.44)\end{array}$ & $\begin{array}{r}10.90 \\
(3.46)\end{array}$ & $\begin{array}{c}13.39 \\
(13.54)\end{array}$ & \multicolumn{2}{|c|}{$\begin{array}{r}8.65 \\
(3.82)\end{array}$} \\
\hline $\begin{array}{l}\text { Monounsaturated FAs (g) } \\
\text { and (\%) }\end{array}$ & $\begin{array}{c}14.86 \\
(10.92)\end{array}$ & & $\begin{array}{c}15.16 \\
(11.12)\end{array}$ & $\begin{array}{l}10.18 \\
(2.82)\end{array}$ & $\begin{array}{l}18.03 \\
(9.92)\end{array}$ & \multicolumn{2}{|c|}{$\begin{array}{l}12.18 \\
(2.38)\end{array}$} \\
\hline $\begin{array}{l}\text { Polyunsaturated FAs (g) } \\
\text { and (\%) }\end{array}$ & $\begin{array}{c}8.03 \\
(6.45)\end{array}$ & & $\begin{array}{c}8.08 \\
(6.43)\end{array}$ & $\begin{array}{c}7.21 \\
(3.52)\end{array}$ & $\begin{array}{c}7.81 \\
(6.35)\end{array}$ & \multicolumn{2}{|c|}{$\begin{array}{r}6.13 \\
(3.95)\end{array}$} \\
\hline $\mathrm{FA}$, omega $3(\mathrm{~g})$ and $(\%)$ & $\begin{array}{c}0.61 \\
(0.69) \\
\end{array}$ & & $\begin{array}{c}0.60 \\
(0.68) \\
\end{array}$ & $\begin{array}{c}0.78 \\
(0.40) \\
\end{array}$ & $\begin{array}{c}0.68 \\
(0.74) \\
\end{array}$ & \multicolumn{2}{|c|}{$\begin{array}{c}0.85 \\
(0.40)\end{array}$} \\
\hline FA, omega $6(\mathrm{~g})$ and $(\%)$ & $\begin{array}{c}5.57 \\
(6.65)\end{array}$ & & $\begin{array}{r}8.08 \\
(6.68)\end{array}$ & $\begin{array}{c}7.21 \\
(1.40)\end{array}$ & $\begin{array}{c}7.81 \\
(6.49)\end{array}$ & \multicolumn{2}{|c|}{$\begin{array}{c}6.13 \\
(1.25)\end{array}$} \\
\hline Index $\omega-6: \omega-3$ (g:g) & 13.4 & & 13.47 & 9.51 & & 13.04 & 11.27 \\
\hline Index U:S (g: g) & 1.63 & & 1.66 & 1.15 & & 1.46 & 0.98 \\
\hline Index $\omega-3:$ TF (g:g) & 0.02 & & 0.09 & 0.11 & & 0.02 & 0.02 \\
\hline Index $\omega-6: \mathrm{TF}$ (g:g) & 0.09 & & 0.08 & 0.78 & & 0.14 & 0.20 \\
\hline Index $\omega-9:$ TF (g:g) & 0.31 & & 0.30 & 1.34 & & 0.32 & 0.27 \\
\hline Index $\omega-6: \omega-9$ (g:g) & 0.5 & & 0.51 & 0.99 & & 0.47 & 0.40 \\
\hline & No signifi & $\begin{array}{l}\text { rgy-adjusted } f_{c} \\
\text { were found al }\end{array}$ & $\begin{array}{l}\text { Villett, } 19 \\
\text { the vari }\end{array}$ & accordi & a t-test. & & \\
\hline & & s: Fatty Acids & otal Fat; & Un Satura & & & \\
\hline
\end{tabular}

Also according to the data in Table 2, in the group of prediabetics with consumption classified in the $2^{\text {nd }}$ and $3 r d$ tertiles of monounsaturated fatty acids ( $\mathrm{g}$ ), a negative relationship was observed, contributing to a reduction in fasting glycemia by about 4.0- $5.0 \mathrm{mg} / \mathrm{dL}$ and in relation to the $2 \mathrm{nd}$ tertile of consumption of the $\mathrm{U}: \mathrm{S}$ index. There was also a positive relationship with consumption in the 2 nd tertile of the $\omega-6: \omega-3$ index and in the 3rd tertile of the $\omega-6: \omega-9$ index. It was observed that the positive relationship increased fasting glucose by about from 4.20 to 5.6 $\mathrm{mg} / \mathrm{dL}$ and contributed to the increase in fasting blood glucose. 
There were no differences for demographic, socioeconomic, epidemiological variables, as well as oxidative stress, inflammatory, lipid profile and lifestyle between the two groups, results not shown. However, different relationships were observed in each group, between fasting blood glucose values and fat consumption, such as: in the pre-diabetic group, inverse relationships were found with the 2 nd and 3rd fat consumption tertiles. to monounsaturated fatty acids (AG) (M) and the U: S Index (I: S); and positive relationships with the consumption of the $\omega-6: \omega-3$ and $\omega-6: \omega-9$ indexes. In the normoglycemic group, a positive relationship was observed with the consumption of total fats, polyunsaturated FA, w-6, indices $w-6$ : w-3, U: S and w-6: w-9.

Table 2: Relationships between terciles of habitual consumption of total fats of different types and with different FA levels and fasting glucose levels in normoglycemic and pre-diabetic individuals.

\begin{tabular}{|c|c|c|c|c|c|c|}
\hline & \multicolumn{3}{|c|}{ Fasting glucose levels in normoglycemic individuals } & \multicolumn{3}{|c|}{ Fasting glucose levels in pre-diabetic individuals } \\
\hline & Mean \pm SD & Coefficient & $P$ & Mean \pm SD & Coefficient & $P$ \\
\hline \multicolumn{7}{|c|}{ Total fat (g) } \\
\hline $2^{\text {nd }}$ tercile & $52.60 \pm 0.60$ & 4.63 & $0.013^{*}$ & $54.40 \pm 0.90$ & 0.05 & 0.974 \\
\hline $3^{\text {rd }}$ tertile & $78.21 \pm 1.91$ & 1.47 & 0.462 & $77.66 \pm 3.42$ & -1.81 & 0.254 \\
\hline \multicolumn{7}{|c|}{ Monounsaturated FAs (g) } \\
\hline $2^{\text {nd }}$ tertile & $12.93 \pm 0.25$ & -1.99 & 0.376 & $15.16 \pm 0.65$ & -5.18 & $0.002^{*}$ \\
\hline $3^{\text {rd }}$ tertile & $25.77 \pm 1.77$ & -3.38 & 0.130 & $24.11 \pm 2.74$ & -4.08 & $0.015^{*}$ \\
\hline \multicolumn{7}{|c|}{ Polyunsaturated FAs (g) } \\
\hline $2^{\text {nd }}$ tertile & $6.34 \pm 0.16$ & 4.93 & $0.026^{*}$ & $6.41 \pm 0.42$ & -1.82 & 0.377 \\
\hline $3^{\text {rd }}$ tertile & $14.95 \pm 1.36$ & 0.86 & 0.695 & $15.02 \pm 1.92$ & -0.72 & 0.757 \\
\hline \multicolumn{7}{|c|}{$F A, \omega-6(g)$} \\
\hline $2^{\text {nd }}$ tertile & $4.28 \pm 0.11$ & 5.50 & $0.012^{*}$ & $4.56 \pm 0.30$ & -2.05 & 0.298 \\
\hline $3^{\text {rd }}$ tertile & $10.81 \pm 0.99$ & 1.30 & 0.552 & $10.50 \pm 1.32$ & -0.35 & 0.885 \\
\hline \multicolumn{7}{|c|}{ Index, $\omega-6: \omega-3$ (g:g) } \\
\hline $2^{\text {nd }}$ tertile & $11.21 \pm 0.22$ & 4.60 & $0.048^{*}$ & $10.42 \pm 0.51$ & 4.20 & $0.031^{*}$ \\
\hline $3^{\text {rd }}$ tertile & $22.33 \pm 1.68$ & 4.80 & $0.038^{*}$ & $27.84 \pm 5.82$ & -0.98 & 0.671 \\
\hline \multicolumn{7}{|c|}{ Index, U:S FAs (g: g) } \\
\hline $2^{\text {nd }}$ tertile & $1.41 \pm 0.02$ & 5.40 & $0.027^{*}$ & $1.39 \pm 0.72$ & -5.51 & $0.034^{*}$ \\
\hline $3^{\text {rd }}$ tertile & $2.60 \pm 0.23$ & 4.15 & 0.124 & $2.77 \pm 0.46$ & 1.54 & 0.400 \\
\hline \multicolumn{7}{|c|}{ Index, $\omega-6: \omega-9$ (g:g) } \\
\hline $2^{\text {nd }}$ tertile & $0.36 \pm 0.01$ & 2.86 & 0.198 & $0.35 \pm 0.17$ & 2.88 & 0.180 \\
\hline $3^{\text {rd }}$ tertile & $1.03 \pm 0.26$ & 6.02 & $0.009 *$ & $0.84 \pm 0.15$ & 5.61 & $0.021^{*}$ \\
\hline \multicolumn{7}{|c|}{ Reference value: 1 st tertile. } \\
\hline \multirow{2}{*}{\multicolumn{7}{|c|}{ Energy-adjusted fats (Willett, 1997). }} \\
\hline & & & & & & \\
\hline & & Abbreviations: & tty Acids; US: & aturated. & & \\
\hline
\end{tabular}

Diet composition, especially fat intake, is associated with the onset or incidence of DM2 [21]. Studies investigating MUFAs have found that these FAs protect against decreased glucose tolerance [22] the results found in the present study in both the normoglycemic group, with a negative correlation between consumption of these FAs and fasting glucose levels, and the prediabetic group, with consumption per tertile values of $8.34 \%$ and $13.23 \%$, respectively, which corroborate the Brazilian Diabetes Guidelines (SBD) [23] in which values of 5 to $15 \%$ of the VET or greater than $12 \%$ are recommended. For PUFAs, especially $\omega-3$ from fish, conflicting evidence has been found. Some studies have found beneficial effects of PUFA consumption [24] or no association between fasting blood glucose and PUFA consumption [25] as in the pre-diabetic group in the present study, although a negative correlation between fasting blood glucose and the U:S FA index, which includes $\omega-3$, was found in this group, which probably contributed to a reduction in insulin resistance, as described in the SBD [23]. Fatty acids from the $\omega-6$ and $\omega-3$ families compete for enzymes involved in desaturation and chain lengthening reactions. Although these enzymes have a greater affinity for acids from the $\omega-3$ family, the conversion of alpha-linolenic acid into AGPI-CL is strongly influenced by the levels of linoleic acid in the diet [25]. 
Thus, the ratio between daily intake of foods that are sources of n- 6 and n-3 fatty acids assumes great importance in human nutrition, resulting in several recommendations that have been established by authors and health agencies in different countries. The values listed in Table 1 show the trend of convergence of the ratio between the fatty acids $\omega-6$ and $\omega-3$ for the range of $4: 1$ to $5: 1$. The ratios of 2: 1 to 3: 1 have been recommended by some authors, as it allows a greater conversion of alpha-linolenic acid into ADH, which reaches its maximum value around 2.3: 1 , as demonstrated [26]. Thus, the ratios between 2: 1 and 4: 1 are more important for people with eating habits that result in a low intake of AEP and ADH. On the other hand, diets based on $w-6 / w-3$ ratios below 1: 1 are not recommended, as they inhibit the transformation of linoleic acid into AGPI-CML [27]. According to Krishnan et al. [28], an interesting and somewhat unexpected finding was a $10 \%$ risk reduction in altered fasting glucose, but not normal fasting glucose values, with moderately high monounsaturated intakes. Thus, for the authors, the altered fasting glucose is not characterized by insulin resistance and the monounsaturated diet is associated with a reduced risk of the onset of the altered fasting glucose, corroborating the results of the present study. Also noting that according to these guidelines [23], monounsaturated fat contributes to increase the fluidity of cell membranes with a consequent reduction in insulin resistance. As in the pre-diabetic group in the present study, surprisingly, some other scholars have shown an increased risk for DM2, associated with increased consumption of fatty acids, including the consumption of isolated $\omega-3$ fatty acids [29].

The PUFA $\omega-3$ is also strongly considered healthy for the heart and good for decreasing the risk of chronic diseases. Epidemiological evidence, however, has been contradictory in some studies, with some showing no relationship between $\omega-3$ consumption and glycaemic control [30] and others showing positive associations between $\omega-3$, PUFAs, and disrupted glycaemic control [31]. However, according to Dalarue et al. [31], Woodman et al. [32], and Carpentier et al. [33], $\omega-3$ was shown to be protective against disruptions in glucose homeostasis in animal studies by increasing the activity of the P13 kinase and GLUT4 in muscles, inhibiting the activity of glucose-6-phosphatase in the liver, and reducing the activities of proinflammatory pathways mediated by cyclooxygenase to improve insulin sensitivity [31], which affects glycaemic control. According to Krishnan et al. [32], dietary intake of PUFAs, specifically $\omega-6$, was related to altered fasting blood glucose in response to the development of altered fasting glycaemia, which was positively associated with the intake of $\omega$-3 and PUFAs but not with the intake of saturated FAs. In the present study, positive relationships between increased glycaemic values and ingestion of the PUFA $\omega-6$ alone and the $\omega-6: \omega-3$ and $\omega-6: \omega-9$ indices were found in the normoglycemic group, and the relationship with the latter ratio was also observed in the pre-diabetic group.

Other significant associations with the intake of specific FAs disappeared when the analyses were adjusted for BMI (results not shown), indicating that body weight and/or body fat percentage may abrogate some potential positive or negative effects of FAs on the incidence of altered fasting blood glucose [33]. In the present study, the relationships found between fasting blood glucose and the intake of different types and proportions of FAs persisted after adjustments for age, sex, BMI, and income. Studies on the effects of different FA indices may be more comprehensive than studies on isolated FAs, such as the FAs represented by the $\omega-6: \omega-3$ index, which compete for the desaturase enzyme. Therefore, high consumption of $\omega-6: \omega-3$ FAs can inhibit the conversion of $\omega-3$ to Docosahexaenoic Acid (DHA), while low consumption can inhibit the desaturation of $\omega-6$ to arachidonic acid [6]. Therefore, further studies on indices reflecting different FAs are recommended considering that various FAs can compete with each other or change in terms of bioavailability. A moderately high dietary intake of $\omega-6$ of $4-5 \%$ of the total daily energy intake was associated with a reduction of approximately $12 \%$ in altered fasting blood glucose. However, higher intake levels counteracted this benefit as observed in the present study in which positive associations between $\omega-6$ in isolation and the $\omega-6: \omega-3, \omega-6$, and $\omega-9$ indices were found with higher $\omega-6$ intake levels (approximately 6.5\%) [27].

\section{Conclusion}

In the present study, no differences between the fat intake variables in relation to either FAs in isolation or the FA indices were found between the two groups studied. However, when evaluating the relationship between fasting blood glucose and FA intake in each group, a negative association was found between the tertiles of MUFA consumption and the U:S FA index in the pre-diabetic group. Therefore, these FAs contribute to reducing fasting blood glucose levels. Positive relationships were observed between fasting blood glucose levels and consumption of most PUFAs either in isolation or in combination. In the normoglycemic group, positive relationships were observed between fasting blood glucose and the consumption per tertile of most PUFAs, which increased blood glucose. A negative correlation was found between the intake values of all normoglycemic individuals and the consumption of MUFAs and $\omega-3$. Therefore, the approach in the present study became more reliable by analysing FA intake indices rather than only FAs in isolation. Thus, considering that fat intake was statistically similar between the two groups, the results of the present study suggest that the amounts of fats consumed should be different between these two groups to avoid increasing glycaemic values and to help reduce them.

\section{Declarations}

a) Ethics Approval and Consent to Participate: The study was approved by the Research Ethics Committee of the CCS/ UFPB, under the protocol number 0569/15.

b) Consent for Publication: Not applicable.

c) Availability of Data and Materials: The data generated in this study are coordinated by Dr. Maria José de Carvalho Costa. 
d) Competing Interests: The authors declare that they have no competing interests.

e) Funding: Not applicable.

\section{Authors' Contributions}

Sônia Cristina Pereira de Oliveira, Cássia Surama Oliveira da Silva, Rafaella Cristhine Pordeus Luna, Thamires Ribeiro Chaves, Mussara Gomes Cavalcanti Alves Monteiro, Keylha Querino de Farias, Jessica Vick Bernardo de Oliveira, Débora Danuse de Lima Silva participated in data acquisition. Raquel Patricia Ataíde Lima, Maria José de Carvalho Costa, Aléssio Tony Cavalcanti de Almeida, Flávia Emília Leite de Lima Ferreira, Alcides da Silva Diniz, Roberto Texeira de Lima, Alcides da Silva Diniz and Alexandre Sérgio Silva participated in the conception and design of the study. Maria da Conceição Rodrigues Gonçalves, Rafaella Cristhine Pordeus Luna, Raquel Patrícia Ataíde Lima and Sônia Cristina Pereira de Oliveira Ramalho Diniz participated in manuscript writing and critical review for important intellectual content. Ronei Marcos de Moraes, Alessio Tony Cavalcanti de Almeida and Maria José de Carvalho Costa participated in data analysis and interpretation.

\section{Acknowledgement}

We thank the funding agencies that made the project possible: Brazilian National Council for Scientific and Technological Development (Conselho Nacional Desenvolvimento Científico e Tecnológico - CNPq), Ministry of Health, and Research Support Foundation of the State of Paraíba (Fundação de Amparo à Pesquisa do Estado da Paraíba - FAPESQ); and the research collaborators (Graduate Program in Nutritional Sciences, University of Paraíba).

\section{References}

1. Matthew C Riddle (2019) American Diabetes Association. Standards of Medical Care in Diabetes - 2019. Diabetes Care 42(1):546-560.

2. Huang T, Beaty T, Li J, Liu H, Zhao w, et al. (2017) Association between dietary fat intake and insulin resistance in chinese child twins. Br J Nutr 117(2): 230-236.

3. Peter C (2019) Metabolic Syndrome-Role of Dietary Fat Type and Quantity. Nutrients 11(7): 1-7.

4. Koh, Jin Ho Johnson, ML Dasari, S LeBrasseur, NK Vuckovic, et al. (2019) TFAM Enhances Fat Oxidation and Attenu High-Fat Diet- Induced. Insulin Resistance in Skeletal Muscle. Diabetes 68(8): 1552-1564.

5. Akbaraly T Scientific Reports. 8 [8620].

6. (2005) Dietary Reference Intakes for Energy, Carbohydrate, Fiber, Fat, Fatty Acids, Cholesterol, Protein and Amino Acids. The National Academies Press.

7. Storlien L H, Jenkins AB, Chisholm DP, Pascoe WS, Wkraegen E (1991) Influence of dietary fat composition on development of insulin resistance in rats: relationship to muscle triglyceride and ômega - 3 fatty acids in muscle phospholipids Diabetes 40: 280-289.

8. Rodriguez MTG, Santos LC, Lopes ACS (2014) Aconselhamento Nutricional para o Diabetes mellitus em Serviço de Atenção primária à Saúde. REME - Revista Mineira de Enfermagem 13(3): 685-690.

9. Tosi F, Guarini P, Olivieri O, Martinelli N (2014) Delta-5 and delta-6 desaturases: crucial enzymes in polyunsaturated fatty acid-related pathways with pleiotropic influences in health and disease. Adv Exp Med Biol 824: 61- 81.
10. Medronho RA (2009) Estudos ecológicos. In: Medronho Ran (Ed.), Epidemiologia. São Paulo Atheneu pp. 265-274.

11. De Oliveira Y, Lima RPA, Luna RCP, Monteiro MGCA, da Silva CSO, et al. (2018) Decrease of DNA methylation levels of the ADRD3 gene in leukocytes is related with sérum folate in eutrophic adults. J Tra nsl Med 16(1): 152.

12. Costa MJ de C, Moraes, RM De, Silva AS, Persunhn DC, et al. (2013) Cycle II of Diagnosis and Intervention of the Food, Nutritional and NonCommunicable Diseases Status of the Population of the Municipality of João Pessoa (II DISANDNT/JP). João Pessoa.

13. IBGE (2010) Brazilian Institute of Geography and Statistics.

14. Kac G, Sichiery R, Gigante DP (2007) Nutritional epidemiology. Scielo.

15. Cochran WG (1977) Sampling techniques. 3rd ed John Wiley Sons 1-448.

16. Silva AHA, Moraes RM De, Maria José de Carvalho Costa (2009) Sampling plan using stratified sampling together with systematic sampling for application of the Nutritional Survey of João Pessoa, Paraíba 5.

17. (1995) Physical Status: the use and interpretation of anthopometry. Reporto f a WHO Expert Committtee 854.

18. Lima, Maria do Rosário Dias de Oliveira Latorre, Maria José de Carvalho Costa, Regina Mara Fisberg (2008) Diet and câncer in Northest Brazil: evolution of eating habits and food group consumption in relation to breast câncer. Cadernos de Saúde Pública 24(4): 820-828.

19. ASCIUTTI LSR (2005) Manual de Porções média em tamanho real baseado no programa Dietsys para estudo de base populacional. Universidade Federal da Paraíba.

20. (2012) Multiple Source Method (MSM).

21. Rahati S, Shahraki M, Arjomand G, Shahraki T (2014) Food pattern, lifestyle and diabetes mellitus. Int J High Risk Behav Addect 3(1).

22. Paniagua JÁ, de la Sacristana AG, Sanches E (2007) A MUFA- rich diet improves pós-prandial glucose, lipid and GLP -1 responses in insulinresistant subjects. J Am Coll Nutr 26: 434 -444.

23. (2017) Diretrizes da Sociedade Brasileira de Diabetes - 2017/2018. Clannad.

24. Zheng JS, Huang T, Yang J, Fu YQ, Li D (2012) Marine N-3 polyunsaturated fatty acids are inversity with risk of type 2 diabetes in Asians: a Systematic review and meta-analysis. Plos One 7(9).

25. Abdelhamid A, Hooper L, Sivakaran R, Hayhoe RPG, Welch A, et al. (2019) The Relationship Between Omega-3, Omega-6 and Total Polyunsaturated Fat and Musculoskeletal Health and Functional Status in Adults: A Systematic Review and Meta-analysis of RCTs. Calcif Tissue Int 105(4): 353-372.

26. Hooper L, Abdelhamid A, Brainard J, Deane KHO, Song F, et al. (2019) Creation of a database to assess effects of omega-3, omega- 6 and total polyunsaturated fats on health: methodology for a set of reviews. BMJ Open 9(5).

27. Brown TJ, Brainard J, Song F, Wang X, Abdelhamid A, et al. (2019) Omega-3, omega- 6 , and total dietary polyunsaturated fat for prevention and treatment of type 2 diabetes mellitus: systematic review and metaanalysis of randomised controlled trials. BMJ 366.

28. Krishnan S, Cooper JA (2014) Effect of dietary fattys acid composition on substrate utilization and body weight maintenance in humans. Eur J Nutr 53(3): 691-710.

29. Hartweg J, Perera R, Montori V, Dinnen S, Neil H A, et al. (2008) Ômega -3 polyunsaturared fatty acids (PUFA) for type 2 diabetes mellitus. Cochrane Database Syst Ver 23(1).

30. Kaushik M, Mozaffarian D, Spiegelmm D, Manson JE, Willett WC, et al. (2009) Long -Chin ômega-3 fatty acids, fish intake, and the risk of type 2 diabetes mellitus. Am J Clin Nutr 90(3): 613-620.

31. Dalarue J, LeFoll C, Corporeau C, Lucas D (2004) N-3 long chain polyunsaturated fatty acids: a nutritional tool to prevent insulin 
resistance. associated to type 2 diabetes and obesity? Reprod Nutr Dev 44(3): 289-299.

32. Woodman RJ, Mori TA, Burke V, Puddey IB, Watts GF, et al. (2002) Effects of purified eicosapentaenoic and docosahexaenoic acids on glycemic control, blood pressure, and sérum lipids in type 2 diabetic patients with treated hypertension. Am J Clin Nutr 76(5): 1007-1015.

33. Carpentier YA, Portois L, Malaisse WJ (2006) N-3 fatty acids the metabolic syndrome. Am Clin Nutr 83(6): 14995-15045.
ISSN: 2574-1241

DOI: 10.26717/BJSTR.2020.25.004262

Sônia Cristina Pereira de Oliveira. Biomed J Sci \& Tech Res

(C) 1 This work is licensed under Creative

Submission Link: https://biomedres.us/submit-manuscript.php

$\begin{array}{ll}\text { BIOMEDICAL } & \text { Assets of Publishing with us } \\ \text { RESEARCHES } & \text { - Global archiving of articles } \\ & \text { - Immediate, unrestricted online access } \\ & \text { - Rigorous Peer Review Process } \\ & \text { - Anttps://biomedres.us/ }\end{array}$

